\title{
Quantifying the effects of post-surgery recovery time on the migration dynamics and survival rates in the wild of acoustically tagged Atlantic Salmon Salmo salar smolts
}

\author{
J. Daniels ${ }^{1 *+}$ (1) , E. B. Brunsdon ${ }^{1,2+}$, G. Chaput ${ }^{3}$, H. J. Dixon ${ }^{4}$, H. Labadie ${ }^{5}$ and J. W. Carr ${ }^{1}$
}

\begin{abstract}
Background: The experimental effects of surgically implanting fish with acoustic transmitters are likely to have negative effects on survival and behaviour. Measuring the extent of these negative effects is important if we wish to extrapolate inferences from tagged animals to un-manipulated animals. In this study, we examine the effect of surgery and post-tagging recovery time on the survival and migration rate of acoustically tagged wild Atlantic Salmon (Salmo salar) smolts through freshwater, estuarine and ocean phases of migration. Four treatment groups were used: pre-smolt captured in the fall that overwintered in a hatchery and were tagged either 75 days prior to release (winter hatchery) or within $24 \mathrm{~h}$ prior to release (spring hatchery) and smolt captured during the spring smolt run, tagged $24 \mathrm{~h}$ prior to release and released during the day (day-released) or night (night-released).
\end{abstract}

Results: The spring hatchery treatment group served as a reference treatment group such that recovery time (comparison to winter hatchery treatment) and hatchery effects (comparison to day-released and night-released treatments) could both be discerned. The hatchery effect increased migration rate, whereas short recovery times and captivity in a hatchery negatively affected survival. These effects were most pronounced within the first 5 days and/or $48 \mathrm{~km}$ downstream post-release, however, the residual recovery time effects appeared to persist during the transition from the estuary into salt water.

Conclusions: Even with smolts originating from the wild and spending relatively little time within the hatchery environment, post-release survival was still negatively affected. Migration speed was faster for hatchery smolts, but is likely only due to their larger size. Recovery time effects were most prominent during the initial migration period in freshwater and again in the transition from the estuary to saltwater which may be due to added stress during these transitional zones. As surgery-related bias will likely never be completely removed from telemetry studies, it is important to quantify and account for these effects in situ when making inferences on the un-manipulated component of the population.

Keywords: Acoustic telemetry, Experimental effects, Captivity effects, Tagging effects, Recovery time

\footnotetext{
*Correspondence: jdaniels@asf.ca

${ }^{\dagger}$ J. Daniels and E. B. Brunsdon contributed equally to the manuscript

${ }^{1}$ Atlantic Salmon Federation, 15 Rankine Mill Road, Chamcook, NB E5B 3A9, Canada

Full list of author information is available at the end of the article
}

\section{Introduction}

Acoustic telemetry has become a broadly applied technology for studying the migration dynamics and for estimating survival rates of many fish species, including juvenile stages of wild Atlantic salmon in both fresh and salt water [1-5]. The use of acoustic technologies

c) The Author(s) 2021. This article is licensed under a Creative Commons Attribution 4.0 International License, which permits use, sharing, adaptation, distribution and reproduction in any medium or format, as long as you give appropriate credit to the original author(s) and the source, provide a link to the Creative Commons licence, and indicate if changes were made. The images or other third party material in this article are included in the article's Creative Commons licence, unless indicated otherwise in a credit line to the material. If material is not included in the article's Creative Commons licence and your intended use is not permitted by statutory regulation or exceeds the permitted use, you will need to obtain permission directly from the copyright holder. To view a copy of this licence, visit http://creativeco mmons.org/licenses/by/4.0/. The Creative Commons Public Domain Dedication waiver (http://creativecommons.org/publicdomain/ zero/1.0/) applies to the data made available in this article, unless otherwise stated in a credit line to the data. 
generally involves the surgical implantation (hereafter "tagging") of acoustic transmitters (hereafter "tags") inside the abdominal cavity of fish which are released back to the wild and remotely detected when in range of receivers placed in the study area. The primary purpose of these studies is to draw inferences on the behaviour and survival of wild untagged animals which are otherwise difficult to observe and monitor.

In the case of such tracking studies, inferences are made based on a number of assumptions regarding the tags and the animals which carry them. Biased inferences of survival and behaviour can result if the tag stops functioning, if the tag is ejected from the tagged animal, if the tag animal is preyed upon and the functional tag is retained in the predator, or if the behaviour and survival of the tagged animal is affected by the handling and tagging procedure [6-12].

With the increasing application of acoustic telemetry in the study of survival and behaviour of fish, it is important to quantify the impact of the experimental manipulation associated with capture and surgical implantation of acoustic transmitters in fish on the biological characteristics of interest. The effects of handling, surgeries, and of tags themselves on salmonid behaviour and survival have been extensively studied in laboratory settings $[7,8$, 12-14], but there is limited in situ research regarding the extent of these effects on tagged animals released to the wild and how long these effects may persist post-tagging. Generally, the release of Atlantic Salmon (Salmo salar) in acoustic telemetry studies has occurred within several hours post-tagging to days $[2,5,15]$. There has been limited research examining the consequences of increasing post-tagging release time [16] in order to minimize the negative effects of the surgical procedure on fish behaviour and survival. Panther et al. [17] recommended holding fish until the surgical incision from tagging is closed (28-70 days), thus reducing the negative effects and potential biases, but this would preclude any research work on actively migrating wild fish such as Atlantic salmon smolts.

We examine the impact of handling and tagging with different recovery periods prior to release on the migration rate and inferred survival of acoustically tagged Atlantic Salmon smolts. A treatment group with a long recovery period post-tagging ( $>70$ days) was constructed by capturing wild Atlantic Salmon juveniles in the late fall, holding them in a captive environment, implanting a subset of these fish with tags during the winter and allowing a long post-surgery recovery period. The potential secondary effects of overwinter captivity on behaviour and survival post-release were also considered by holding a subset of the fall captured juveniles in the hatchery, but only tagging the fish prior to release with a very short recovery period (several hours) in the spring. Both groups of captive juveniles were subsequently released at the same location and time as wild smolts, which were collected and tagged during the spring smolt migration. The fish held in the hatchery and tagged in the spring (hereafter referred to as the spring hatchery treatment) were used as the reference treatment. Spring captured and tagged (i.e. spring wild) relative to spring hatchery was interpreted as the effect of hatchery holding, whereas the fish held in captivity and tagged in the winter (i.e. winter hatchery) relative to the spring hatchery was interpreted as the recovery time effect. Our expectation was that the tagging manipulation and short recovery time would negatively affect survival and migration rate compared to fish with a long recovery time. We also expected that a hatchery holding effect would negatively impact survival and migration post-release relative to the wild capture treatment.

Another consideration in post-release strategies is related to the time of day when tagged fish are released. Vollset et al. [18] reported that acoustically tagged wild Atlantic Salmon smolts released in the evening had higher estimated survival rates in freshwater and in a ford than tagged smolts released in the morning. The time of release of tagged and recovered Atlantic Salmon smolts is an important consideration given that during active migration, Atlantic Salmon smolts in freshwater generally move at night and rest or take shelter during the day [19-21] at least during the early stages of migration. This nocturnal migration of smolts has been interpreted as a strategy for predator avoidance [20,22]. As many of the predators of migrating salmon smolts including birds and fish are visual predators, releasing tagged smolts during the day may further increase their susceptibility to predation relative to wild untagged fish. Smolts released during the night after post-surgery recovery may also use this time to further recover from the stress of capture and handling [23]. We examined the effect of time of release by releasing the wild captured and tagged smolts either during the day following recovery or as an evening release. Our expectation was that releasing smolts in the evening at dusk would enhance their survival rates relative to tagged smolts released during the day. This effect was only examined for the wild smolt group captured in the spring.

\section{Materials and methods \\ Study location and study species}

The Northwest Miramichi River is the second largest branch of the Miramichi River in New Brunswick Canada (Fig. 1). It drains a catchment area of $3,900 \mathrm{~km}^{2}$ into the main stem of the Miramichi where it continues into the Gulf of St Lawrence. Atlantic Salmon smolts mostly 

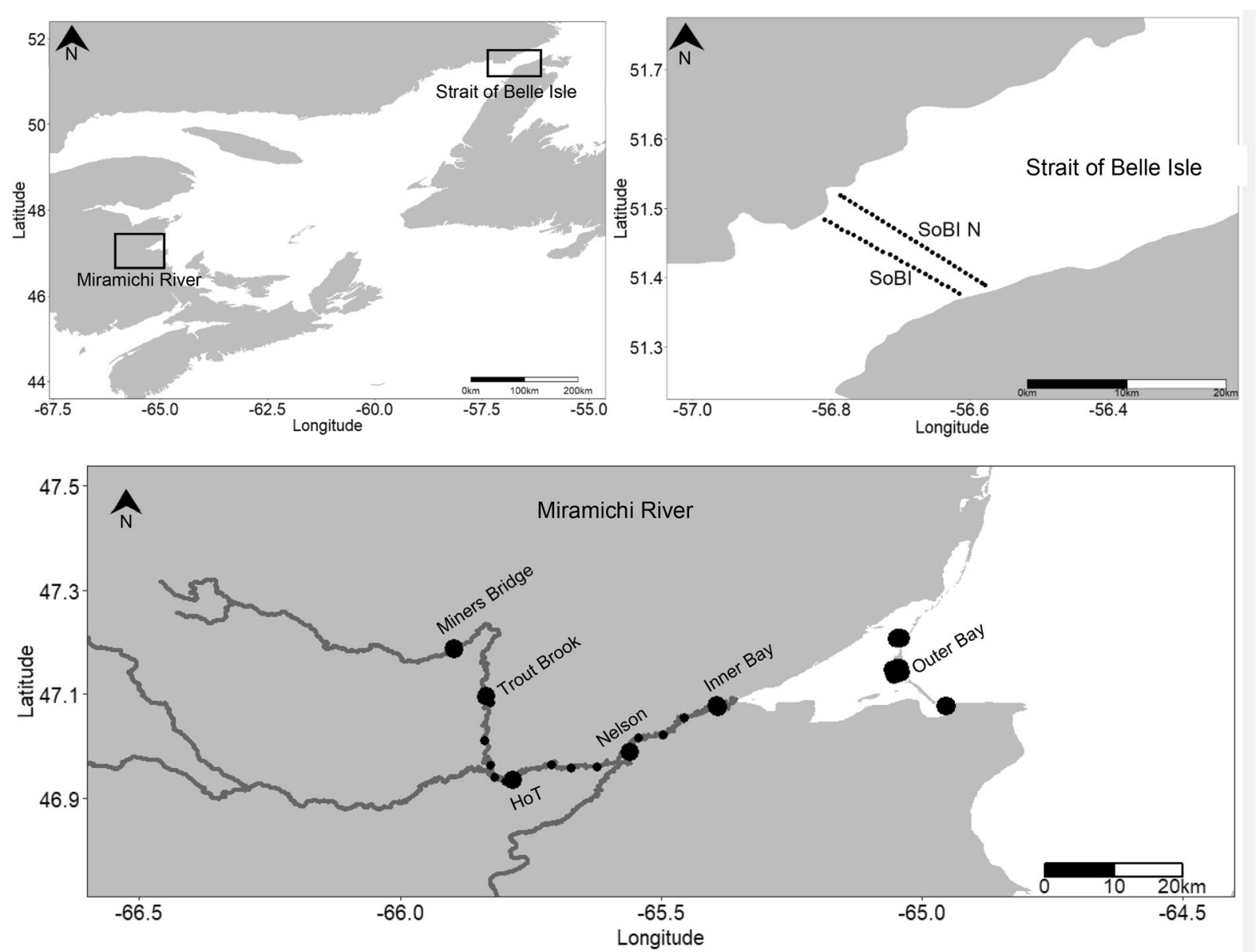

Fig. 1 Map of capture/release sites and receiver gate locations in the Northwest Miramichi River, the Miramichi River and Bay, and the Strait of Belle Isle. The capture of pre-smolt occurred at both Miners Bridge and Trout Brook, whereas smolt capture in the spring only occurred at Trout Brook. All fish were released at Miners Bridge. Receiver gates were placed at the head of tide (HoT), the intersection of the Northwest Miramichi River and the main stem of the Miramichi River (Nelson), the entrance into the Miramichi Bay (Inner Bay), the exit of the Miramichi Bay (Outer Bay), and the Strait of Belle Isle (SoBI and SoBI N). Smaller circles in the Miramichi River denote receiver locations where survival was not quantified, but were used to discern between striped bass and smolt movement patterns

comprised 2- to 4-year-old juveniles with a fork length range of 11 to $17 \mathrm{~cm}$, and a mean size of 13 to $14 \mathrm{~cm}$ [24]. Based on acoustic tracking studies, after smolts exit from the river, they migrate northward through the Gulf of St Lawrence and enter the Labrador Sea via the Strait of Belle Isle (SoBI; Fig. 1; [5]).

\section{Fall collection of Atlantic Salmon pre-smolt juveniles}

A backpack electrofisher (Smith-Root; model LR24) was used to collect wild large juveniles ( $>11 \mathrm{~cm}$ fork length), assumed to be potential smolt migrants the following spring. Juveniles were collected from two sites (Fig. 1; Table 1): Miners Bridge on October 9, $2015(n=31)$ and Trout Brook on October 13, $2015(n=52)$. The fish were transported in oxygenated tanks to a salmonid hatchery located at the Miramichi Salmon Conservation Centre in South Esk, New Brunswick, Canada. Juvenile salmon were held in a $1.8 \mathrm{~m}$ circular fibreglass tank and maintained on flow-through well water at a temperature of approximately $7{ }^{\circ} \mathrm{C}$ and natural photoperiod. Fish were fed a freeze-dried krill diet for the first week, then gradually transitioned to a semi-moist pellet diet, followed by a hard pellet diet $(1.2 \mathrm{~mm}$ and $1.5 \mathrm{~mm})$. Fish were fed two to three times per day to satiation throughout the period of captive rearing.

Survival rate in captivity was high; from the time of capture to March 6, 2016, 72 of the 83 juveniles were still alive, an $87 \%$ survival rate. For the first treatment (winter hatchery), 30 fish were randomly selected and taken off feed on March 6 (2016) and tagged on March 8 (72 days prior to release) and then placed in a separate holding tank from the untagged fish at which point 
Table 1 Experimental details and observed detections of smolts per receiver array

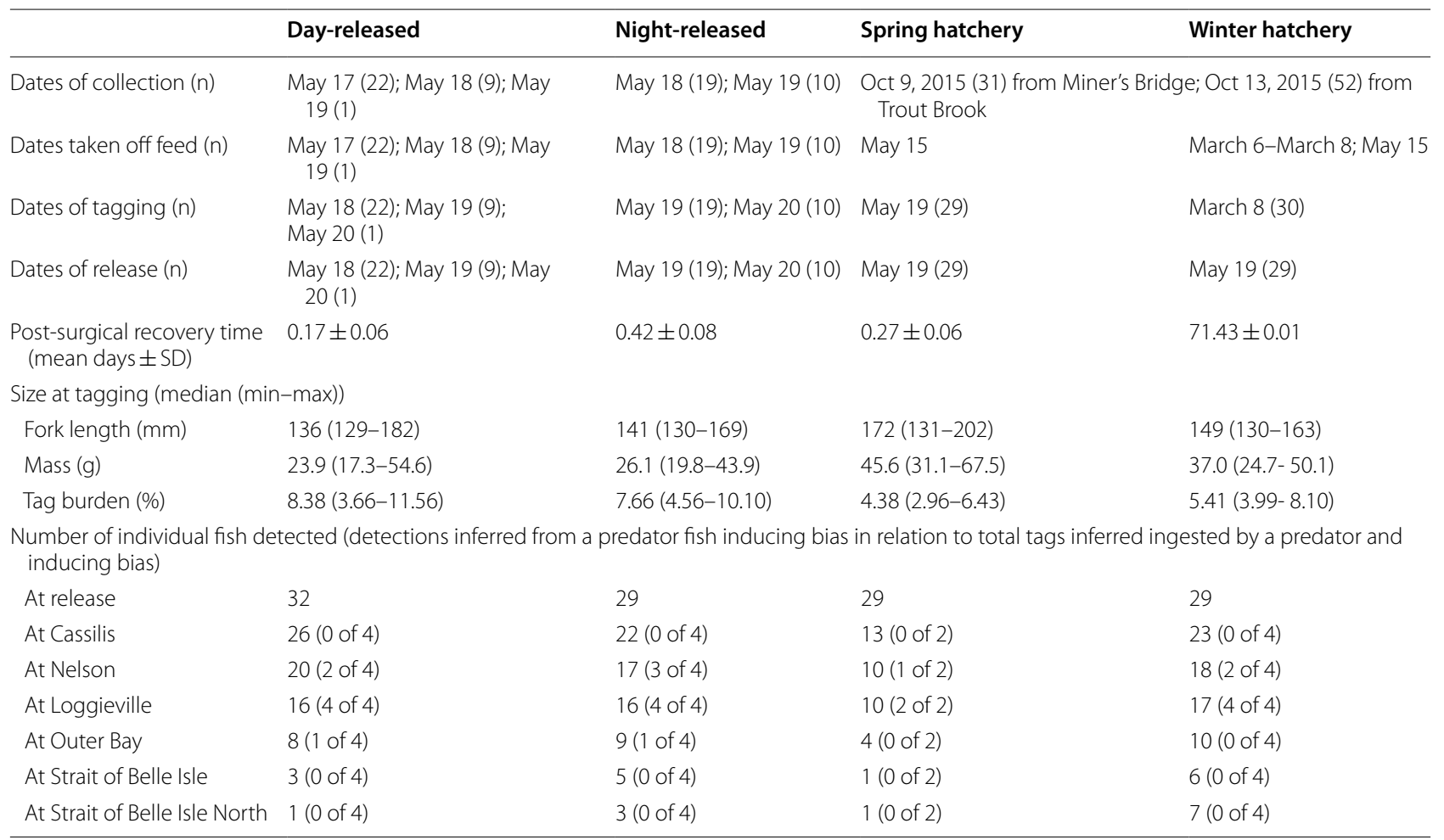

For the detections, the values in parentheses are the number of tags detected at each array inferred to be of a smolt tag ingested by a predator which induced predation bias rather than of a free-swimming smolt relative to the total number of unique tags which were inferred to have been ingested by a predator and induced predation bias over the whole migration period. Fork length, mass tag burden measured on March 8th for Winter hatchery treatment while remaining treatment groups were measured between May 18th and the 20th

feeding was resumed. One of the 30 tagged juveniles died 26 days post-surgery. Eight of the untagged fish were culled and sent to Department of Fisheries and Oceans Canada laboratory for disease screening/release approval. The tagged fish group and the untagged group were taken off feed on May 15, 4 days before being transferred to oxygenated $9.0{ }^{\circ} \mathrm{C}$ containers and transported by truck to the Miners Bridge release site in the Northwest Miramichi (Fig. 1; Table 1), a trip which took approximately $45 \mathrm{~min}$. Upon arrival at the release site, river water was gradually added to the transport containers for approximately $30 \mathrm{~min}$ for purposes of temperature and water chemistry acclimation. River water temperatures at the time of transfer ranged from 8.5 to $9.5{ }^{\circ} \mathrm{C}$. The winter tagged captive smolts were released as a group immediately following acclimation. The remaining 34 untagged captive smolts were transported to the release site where 29 were tagged for the second treatment group (spring hatchery), held for a minimum of one hour to allow restoration of equilibrium of the fish, then released (Table 1). The remaining 5 untagged captive smolts were released at the release site. Smolts from the two captive treatment groups were released on May 19, 2016.

\section{Collection of wild Atlantic Salmon smolts for day and night releases}

A total of 61 wild salmon smolts were selected during May 17-19 (2016) from catches in a rotary screw trap set at Trout Brook in the Northwest Miramichi (Fig. 1; Table 1). Only smolts with a fork length $\geq 13 \mathrm{~cm}$ were selected for the experiment to accommodate the size of the acoustic tag. All smolts selected for tagging were held in in-stream tanks for 20 to $24 \mathrm{~h}$ prior to tagging to allow for digestion of stomach contents. Smolts were then transported by truck in oxygenated tanks to the Miners Bridge release site, a trip which took approximately $15 \mathrm{~min}$, where surgery and tagging were conducted. After surgery, smolts were held in plastic flow-through streamside containers (length: $80 \mathrm{~cm}$; depth: $35 \mathrm{~cm}$; width: $50 \mathrm{~cm}$ ) for a minimum of one hour after equilibrium had been restored before being released (Table 1). Collected smolts were divided daily into two treatment groups. The first treatment group, consisting of a total of 32 smolts, was tagged and released during the day (day-released). The second treatment group, consisting of 29 smolts, was tagged and released in the late evening at 2200 hours, approximately 1-h post-sunset (night-released). Wild tagged smolts from these treatment groups were released 
on May 18, 2016 (22 for day release), May 19, 2016 (9 and 19 for day and night released, respectively) and May 20, 2016 ( 1 and 10 for day and night released, respectively; Table 1). The combination of both day-released and night-released treatments is referred to as a spring wild treatment.

\section{Tagging procedure}

The tagging procedure was the same for all treatment groups and as previously described by Daniels et al. [10] and Chaput et al. [5]. Prior to tagging all acoustic transmitters were inspected to ensure they were operational. Fish were anaesthetized using clove oil $(40 \mathrm{mg} / \mathrm{L}$ concentration) until loss of equilibrium and very little operculum movement was observed (generally $3-5 \mathrm{~min}$ ). All tools and tags were disinfected in anhydrous ethyl alcohol and rinsed in distilled water. Wet weight $(\mathrm{g})$ and fork length $(\mathrm{mm})$ were taken before the fish was placed ventral side up on a v-shaped operating board lined with a chamois leather. An $\approx 11$-mm incision was made along the mid-ventral line about $10 \mathrm{~mm}$ anterior to the pelvic girdle. Acoustic tags (Innovasea Marine Systems Canada, Inc., Halifax, NS; model V8; diameter $=8 \mathrm{~mm}$, length $=20.5 \mathrm{~mm}$, weight in air $=2.0 \mathrm{~g}$; output $=144 \mathrm{~dB}$ re $1 \mathrm{uPa} @ 1 \mathrm{~m}$, transmission cycle=random 25-55 s) were inserted into the body cavity of the fish via the incision. The fish's gills and body were continuously irrigated with anaesthetic or water during the surgery while avoiding the incision area. One suture per $5 \mathrm{~mm}$ of incision (typically two sutures) was used to close the incision and the fish was placed in a recovery bath, with aerated water, for observation. Two surgeons tagged the same number of smolts in each treatment. The acoustic tags for the winter tagged group were programmed for a delayed start on May 14, 2016.

Fish from all treatment groups were only weighed and measured at time of tagging. Winter tagged hatchery fish were weighed and measured at the time of surgery (March 8) but not at the time of release (May 19) as we did not want to introduce anaesthetic and handling effects immediately before release. The captive treatment group tagged in the winter was of intermediate size at time of tagging (median fork length $149 \mathrm{~mm}$ ) to captive fish tagged in the spring (median $\mathrm{FL}=172 \mathrm{~mm}$ ) and to wild smolts captured and tagged in the spring (median $\mathrm{FL}=138 \mathrm{~mm}$; Fig. 2).

\section{Receiver deployment}

Arrays of acoustic receivers (Innovasea Marine Systems Canada, Inc., Halifax, NS; model VR2W) were deployed within the Miramichi River and bay and at the SoBI northern exit of the Gulf of St. Lawrence (Fig. 1). All receivers were attached to moorings consisting of varying

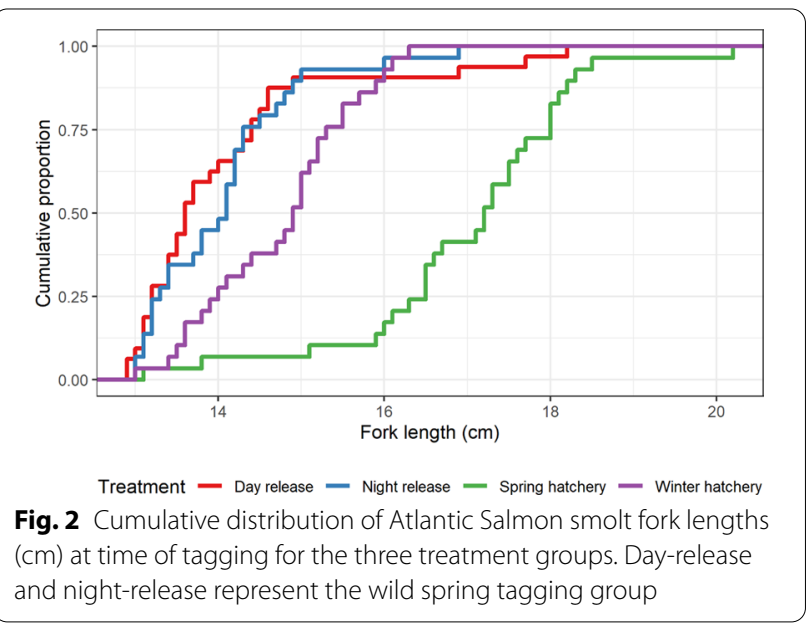

weight anchors (depending on current and water surface conditions), line and surface floats. Receivers within the river were suspended approximately $4 \mathrm{~m}$ below the surface floats whereas receivers at the SoBI were suspended $20 \mathrm{~m}$ below the surface. Sinking line was used from the surface floats to a nylon swivel located below the receiver, which in turn was attached to the anchor with floating line. At the SoBI a second gate was deployed $3.5 \mathrm{~km}$ north of the first gate to allow the estimation of detection probabilities and survival to the primary SoBI array (see statistical methodology). The number of receivers used at each gate was based on manufacturer recommendations of $400 \mathrm{~m}$ detection ranges for V8 tags; receivers were spaced approximately $800 \mathrm{~m}$ apart and $400 \mathrm{~m}$ from each side of the shoreline. There was a total of 16 gates between the release location to SoBI (Fig. 1). Survival and timing were estimated at a subset of receiver gates located at the head of tide (HoT), Nelson, Inner Bay, Outer Bay and SoBI, situated 48.8, 70, 87.3, 114.3, and $899.3 \mathrm{~km}$ from the release site, respectively (for additional details on receiver deployments and retrieval see [5, 10]; Additional file 1).

\section{Statistical analyses \\ Smolt size}

Similarities among the treatment groups for length and tag burden (tag weight as \% of smolt weight in air) at tagging were examined with a one-way ANOVA and post hoc pairwise t-test comparisons with the Holm correction [25] to control for Type I errors.

\section{Survival and probability of detection model}

Sequential survival rates of tagged smolts from release to the SoBI line were estimated using a state-space formulation of a Cormack-Jolly-Seber (CJS) model [26, 27]. The state-space parameterization of the CJS model 
constructs distinct processes for the unobserved survival $(\phi)$ and the observed detections $(p)$. We refer to survival as the joint probability of a tagged fish surviving to pass a receiver array and of the tag being detected at that array. The unobserved survival process (Eq. 1) is modelled as random draws from a Bernoulli distribution, where $z(i, j)$ is conditional on $z(i, j-1)$, whether fish $i$ is alive (1) or dead (0) at the previous detection point:

$$
z(i, j) \mid z(i, j-1), \emptyset_{j} \sim \operatorname{Bernoulli}\left(z(i, j-1) \emptyset_{j}\right),
$$

with parameter $\varnothing_{j}$ the probability of survival within the zone defined by detection arrays $j-1$ to $j$ and $j$ corresponding to the sequence of post-release detection points.

The detections $(y(i, j))$ are modelled as independent Bernoulli random variables, conditional on the $z(i, j)$ 's and the probability of detection $\left(p_{j}\right)$ :

$$
y(i, j) \mid z(i, j), p_{j} \sim \operatorname{Bernoulli}\left(z(i, j) p_{j}\right),
$$

with parameter $p_{j}$ the probability of detection at array $j$.

The parameters $p$ and $\phi$ are proportions bounded on the range $[0,1]$ but are logit-transformed for flexibility in parameterization of survival factors and to improve model convergence.

It was assumed that the probabilities of detection of individual tags (i) at each array line (j) were similar across treatments (i|t), but could differ among arrays and these were given uninformative priors $\left(p_{i \mid t, j} \sim \operatorname{Beta}\left(a_{j}, b_{j}\right)\right.$ with $\left.a_{j}=b_{j}=1\right)$. To determine if there were differences in survival rates by zone and treatment (winter hatchery, spring hatchery, spring wild), we modelled the survival process using a fixed effects model:

$$
\begin{aligned}
& y_{i \mid t, j} \sim \operatorname{Bern}\left(\varnothing_{i \mid t, j}\right), \\
& \operatorname{logit}\left(\varnothing_{i \mid t, j}\right)=\mu_{j}+\alpha_{j} * T_{i \mid 1}+\beta_{j} * T_{i \mid 2},
\end{aligned}
$$

with $\mu_{j}$ the average logit survival of fish of the reference treatment group in zone $\mathbf{j} ; \alpha_{j}$ the difference from the reference treatment group in logit survival of fish in treatment $1\left(T_{i \mid 1}\right)$ in zone $\mathrm{j} ; T_{i \mid 1}$ an indicator variable that equals 1 if the fish is of treatment 1 and 0 otherwise; $\beta_{j}$ the difference from the reference treatment group in logit survival of fish in treatment $2\left(T_{i \mid 2}\right)$ in zone j; $T_{i \mid 2}$ an indicator variable that equals 1 if the fish is of treatment 2 and 0 otherwise.

Note that the fish in the reference treatment have $T_{i \mid 1}=0$ and $T_{i \mid 2}=0$ hence logit survival of the reference group in zone $\mathrm{j}=\mu_{j}$. We set the spring hatchery treatment group as the reference treatment because we were interested in estimating the adjusted survival rate of wild captured smolts with minimal recovery time effect (i.e. long recovery time). However, to do so, we also had to account for the effect of captive holding of fish for several months. Spring wild (Treatment 1) relative to spring hatchery represents the hatchery holding effect $(\alpha)$, whereas Winter hatchery (Treatment 2) relative to the spring hatchery represents the recovery time effect $(\beta)$. From Eq. 3, the adjusted logit survival rate of wild captured smolts with a long recovery time is the sum of the posterior distributions of $\mu_{j}, \alpha_{j}$ and $\beta_{j}$. The odds ratio of survival among treatment groups is used to make inference on the effect of captivity in the hatchery (spring hatchery tagged relative to spring wild tagged) and the effect of recovery period (spring hatchery tagged relative to winter hatchery tagged).

Several model structures for survival were examined and the final model retained for assessing treatment effects modelled the survival rates through the Gulf of St. Lawrence zone, between the Outer Bay and the SoBI array, as similar across treatments. In this way, we limited our analysis of treatment dependent survival rates by zone from the point of release to detection at the Outer Bay arrays. Noninformative priors, on the logit scale, were assumed for the survival parameters by zone $\left(\mu_{j}, \alpha_{j}, \beta_{j}\right)$ as :

$$
\mu_{j}, \alpha_{j}, \beta_{j} \sim \operatorname{Normal}\left(0, \sigma^{2}\right) \text { with } \sigma^{-2}=0.368
$$

[28].

Details of a similar CJS model to the one used in this study are found in Chaput et al. [5].

The model was coded in OpenBUGS (version 3.2.3) and run with two chains of 15,000 iterations with a burn-in of 10,000 and thinned by 10 to produce 10,000 MCMC values for summaries of the posterior distributions. Model convergence was assessed visually through examining trace plots of each Markov chain as well as ensuring Gelman-Rubin statistics were $<1.1$ for the estimated parameters.

\section{Migration speed to gates}

Migration speed to each gate was calculated as the distance $(\mathrm{km})$ divided by the time between first detections from the current and preceding gate. Speed was not standardized by body lengths due to the uncertainty of size for the winter hatchery treatment at the time of migration. A mixed effects ANOVA was performed with smolt ID nested in gate as random effects to account for individual smolt having repeated migration speeds to multiple gates. AIC scores were examined for competing models for all combinations that included fixed effects of treatment, gate, fork length, and all 
two-way interactions. Post hoc pairwise comparisons were conducted using least squared means and resulting p-values were Holm's adjusted.

\section{Potential source of predation-induced survival and migration rate bias}

In the NW Miramichi River, concurrent intra-species acoustic telemetry studies involving Atlantic Salmon smolts and striped bass (Morone saxatilis) demonstrated considerable spatial and temporal overlap, the occurrence of predation of acoustically tagged salmon smolts, with resultant predation bias potential for survival and migration rate estimates [10, 11]. Daniels et al. [11] suggested migration rates based on the first detections at arrays presented the least amount of predation-induced bias; this is the timing methodology we used. With respect to survival estimates, predation-induced bias is introduced when a tagged smolt is consumed by a predator and the tag is detected further along the migration route from within the predator's gastrointestinal tract. Based on detection patterns at the full set of receivers in the river and bay, tags implanted in smolts were subjectively classified into one of two categories; (1) pattern consistent with smolt behaviour and, (2) pattern consistent with striped bass behaviour and presents predation-induced bias. Predation-induced bias in the context of the model structure used here is introduced when a tagged animal is preyed upon and the functional tag within the predator is detected downstream of the predation event. Therefore, the number of tags including predation-induced bias and the number of tagged smolts predated are not synonymous. Subjective assignments were made based on expert opinion by interpreting sequential detection patterns of smolts detected at the SoBI and acoustically tagged striped bass monitored within the same study site and year (see Daniels et al. [10] for details and examples). CJS models were run with and without total unique tags inferred to introduce predation-induced bias to explore potential interactions between predation-induced bias and recovery time-induced bias. It should be noted, however, that an increased rate of predation and therefore, the potential rate of predation-induced bias, could be an indirect result of recovery time effects.

\section{Results}

\section{Smolts size}

Overall, there was a significant difference in fork length ( $F=43.24 ; d f=3 ; p<0.0001)$ between treatment groups. Post hoc treatment comparisons showed only spring hatchery smolts to be significantly longer than all other treatments (Table 1; Fig. 2). Tag burden also differed significantly between treatment groups $(F=59.73 ; d f=3$; $p<0.0001)$. Post hoc comparisons showed that spring hatchery smolts tag burdens were smaller than all other treatment groups while winter hatchery smolts had smaller tag burdens compared to day- and night-released wild smolts (Table 1). Day-released and night-released wild spring smolt groups had similar tag burdens.

\section{Day-release vs night-release}

There were no significant differences in the apparent survival and migration rate to arrays of day-released compared to night-released wild smolts (Table 2). Therefore, day-released and night-released treatments were combined for comparisons to the captive treatments.

\section{Observed detections}

Observed detections of tagged smolts varied between zones and treatments. Of the 61, 29, and 29 tagged smolts released for the spring wild, winter hatchery, and spring hatchery treatments, 50 (82\%), 25 (86\%), and 13 (45\%) smolts, respectively, were subsequently detected at downstream receivers. Only 13 of 29 tags $(45 \%)$ of the spring hatchery treatment were detected

Table 2 The probability of survival and migration speed ( $\mathrm{km} / \mathrm{day})$ of day- and night-released treatments between each gate (head of tide=HoT; the intersection of the Northwest Miramichi River and the main stem of the Miramichi River= Nelson; the entrance into the Miramichi Bay= Inner Bay; the exit of the Miramichi Bay= Outer Bay; Strait of Belle Isle $=\mathrm{SoBI}$ ) and cumulative survival from release to SoBI

\begin{tabular}{|c|c|c|c|c|c|}
\hline \multirow[t]{2}{*}{ Gate } & \multirow[t]{2}{*}{ Distance (km) } & \multicolumn{2}{|c|}{ Survival (mean $(95 \% \mathrm{Cl}))$} & \multicolumn{2}{|c|}{ Migration speed (mean \pm SD (n)) } \\
\hline & & Day-released & Night-released & Day-released & Night-released \\
\hline Release-HoT & 48.8 & $0.817(0.660-0.940)$ & $0.759(0.579-0.906)$ & $9.96 \pm 3.03(22)$ & $11.63 \pm 4.86(18)$ \\
\hline HoT-Nelson & 21.2 & $0.668(0.470-0.838)$ & $0.654(0.440-0.838)$ & $21.68 \pm 12.00(15)$ & $15.30 \pm 11.83(12)$ \\
\hline Nelson-Inner Bay & 17.3 & $0.910(0.734-0.996)$ & $0.931(0.766-0.998)$ & $39.95 \pm 31.78(13)$ & $51.82 \pm 37.01(13)$ \\
\hline Inner Bay-Outer Bay & 27 & $0.592(0.327-0.867)$ & $0.666(0.393-0.923)$ & $24.61 \pm 12.16(6)$ & $28.89 \pm 12.59(8)$ \\
\hline Outer Bay-SoBI & 785 & $0.566(0.217-0.937)$ & $0.646(0.302-0.960)$ & $16.26 \pm 0.86(3)$ & $16.37 \pm 1.13(5)$ \\
\hline Release-SoBI & 899.3 & $0.164(0.054-0.326)$ & $0.197(0.074-0.366)$ & NA & $\mathrm{NA}$ \\
\hline
\end{tabular}


at the HoT array, much lower than the $79 \%$ of tags from the winter hatchery treatment and the spring wild treatment detected at the HoT array. The relative reduction in detections between the HoT and the outer bay array was the same for the spring wild treatment and the spring hatchery treatment $(-61 \%)$ in contrast to the relatively lower reduction in tags detected for the hatchery winter treatment $(-52 \%)$. There was no evidence of size selection in survival between receiver arrays and within treatments (See Additional file 1).

\section{Predation-induced bias}

Based on the interpretation of detection patterns, 8 of 61 tags from spring wild tagging, 2 of 29 tags from spring hatchery tagging, and 4 of 29 tags from winter hatchery tagging were inferred to have been predated by striped bass and introduce predation bias (Table 1). This represents $13 \%$ of tags of the spring wild release group (95\% confidence interval range, 5\%-20\%), 7\% (95\% CI $1 \%-17 \%)$ of the spring hatchery release group, and $14 \%$ (95\% CI 3\%-26\%) of the winter hatchery release group. Based on tags detected post-release, the number of tags with detections consistent with striped bass movement and inducing predation bias was similar among treatments; $17 \%$ (95\% C.I 6\%-24\%) of the spring wild group, $15 \%(95 \%$ CI $2 \%-34 \%)$ of the spring hatchery group, and $17 \%$ (95\% CI 4\%-30\%) for the winter hatchery group. As there was no evidence of differential rates of predation-induced bias between treatments, CJS model results including total unique tags are presented and discussed.

\section{Smolt survival and probability of detection and adjusted survival rate}

The mean probabilities of detection at the arrays within the river and estuary were generally high, ranging from 0.914 to 0.984 . The outer bay and SoBI arrays, however, were estimated to have lower detection probabilities, with mean values of 0.731 and 0.702 , respectively (Fig. 3), consistent with previous analyses [5].

Evidence of statistically significant negative hatchery and recovery time effects were present from release to the HoT array (Fig. 5). There was no evidence of hatchery or recovery time effects present through the estuary (HoT to inner bay). A potentially significant $(p=0.06)$ negative recovery time effect was noted between the inner and outer Miramichi Bay, whereas there was no evidence of a hatchery effect in this zone (Fig. 4).

Results suggest that the winter hatchery treatment group may have had slightly improved survival through the bay in comparison to the other treatments, however, small sample sizes preclude firm conclusions (Fig. 3). Throughout all regions survival odds generally favoured the winter hatchery treatment (Fig. 3; Table 3).
An extended recovery period prior to release improved the odds of survival post-release (winter hatchery treatment) with survival odds of just under 2.53; this is due to the poor survival immediately post-release of the spring hatchery treatment (Fig. 5; Table 3). The survival odds of a long recovery period were also improved relative to wild spring tagged smolts, with a median value of 1.38 favouring the survival of the long recovery treatment. After the initial mortalities in the freshwater portion of the river, above the HoT, the survival odds still favoured the long recovery period treatment, 1.34 to 1.47 relative to the short recovery treatments, however the statistical evidence for this was weaker ( $p$-values 0.11 to 0.14 ) because of small sample sizes. A hatchery effect was noted for the initial survival odds, favouring by a factor of 1.83 the survival of spring wild smolts relative to the spring hatchery treatment (Table 3). After the initial triage of compromised fish from the spring hatchery treatment, the odds of survival through the estuary and bay were similar $(1.1, p=0.39)$ for spring wild and spring hatchery fish (Table 3 ).

The adjusted survival after controlling for both recovery time and hatchery effects suggests that survival for untagged fish could be much higher than inferred from tagged animals during the initial phase of the migration through freshwater. Due to subsequent decreases in sample size throughout the remainder of the migration a great deal of uncertainty prohibits clear expectations. Despite this uncertainty, there was a reasonable increase in adjusted survival (median 28\%) in comparison to the spring wild treatment between the inner and outer bay (Fig. 5).

\section{Migration speed}

The best fitting model according to AIC scores included treatment, gate, and the interaction of treatment and gate as fixed effects. Mixed effects ANOVA showed significant differences between treatments $(F=5.85 ; p<0.01)$, gates $(F=42.21 ; p<0.01)$, and the interaction of treatment and gate $(F=3.44 ; p<0.01)$. Pairwise comparisons between treatment group migration speeds showed spring wild smolts had significantly slower migration speeds compared to winter hatchery $(t=5.54 ; p \leq 0.01)$ and spring hatchery $(t=3.06 ; p<0.01)$ treatments between release to $\mathrm{HoT}$ (Fig. 6). From release to HoT, spring hatchery and winter hatchery smolt migration speeds did not differ $(t=1.32 ; p=0.19)$. There were no other differences between treatment migration speed comparisons between any of the other gates $(t \leq 1.27 ; p \geq 0.62$; Fig. 6). 

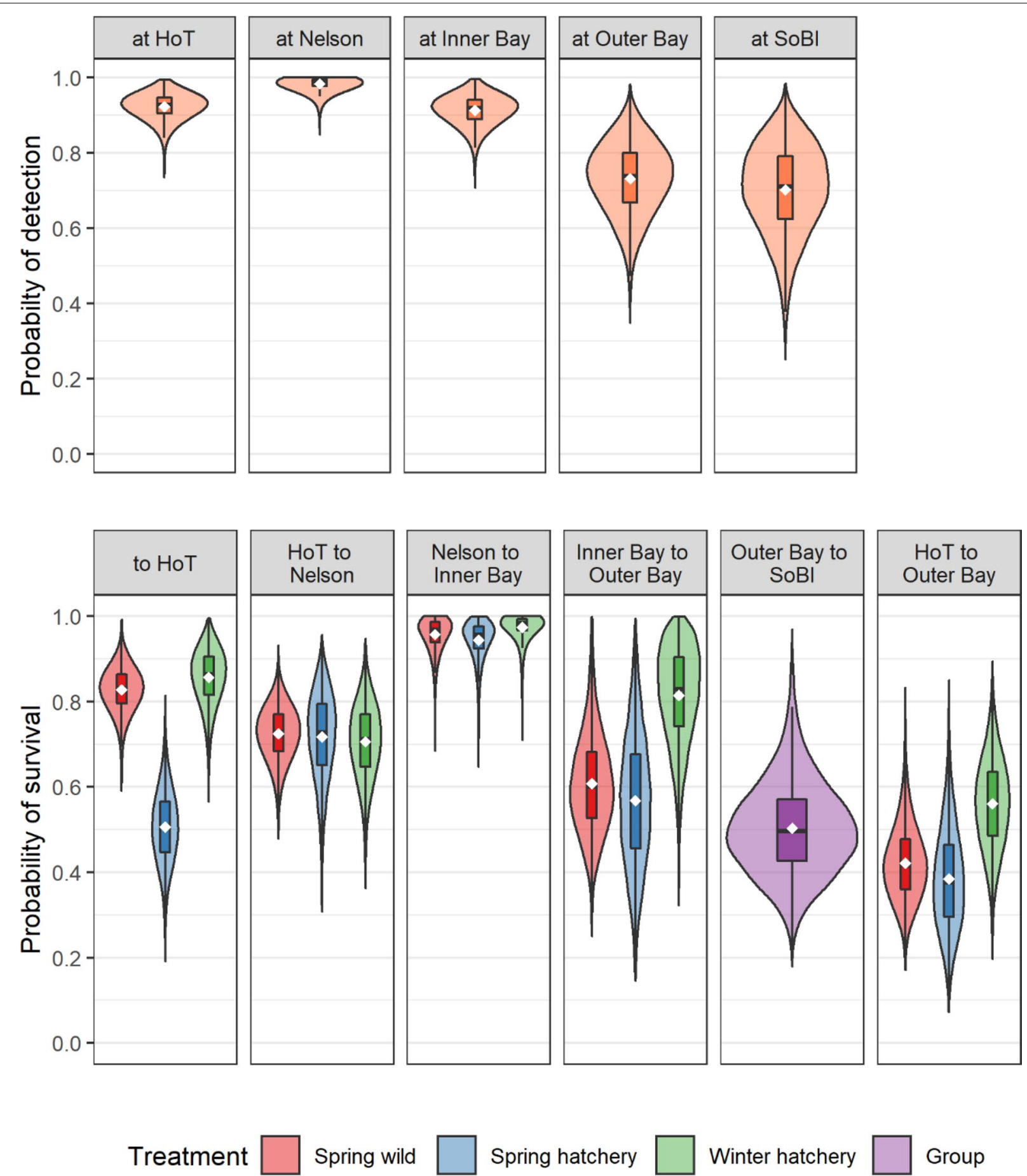

Winter hatchery

Group

Fig. 3 Posterior distributions of probability of detection at (top row) and probability of survival between (bottom row) gates and cumulative survival through the estuary and bay (HoT to Outer Bay). White symbols in the violin plots are the mean, whereas the internal rectangle and dash are the interquartile range and median, respectively

\section{Discussion}

We report on a field experiment to assess the effects of handling/tagging on migrating Atlantic Salmon smolts and on inferences of survival and migration rates using acoustic technologies. In particular, we assess the extent to which post-surgery recovery time can affect those 


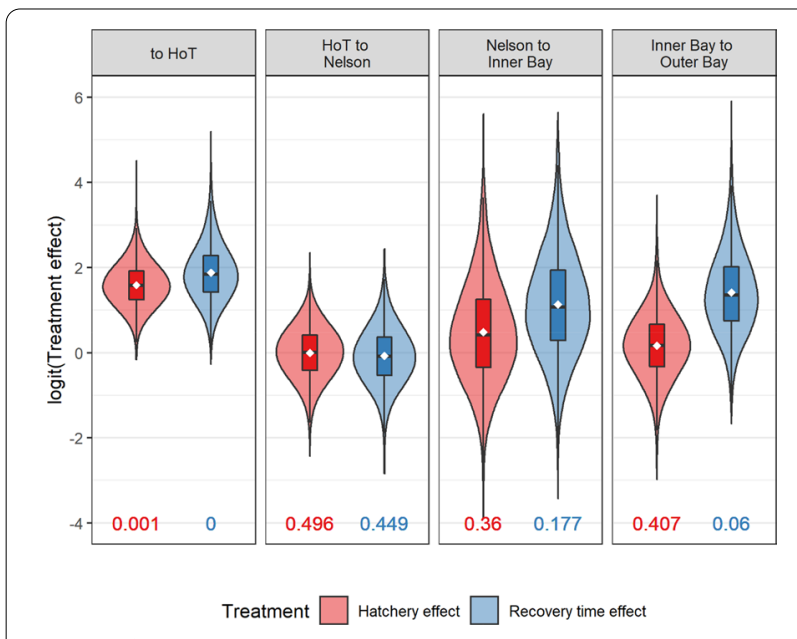

Fig. 4 Inferred effect size on the logit scale of differences in survival rates relative to the reference treatment (spring hatchery) for spring wild tagged and winter hatchery tagged smolts by zone within the Miramichi River and bay. Violin plots are interpreted as in Fig. 3. The $p$-values for the treatment effect by zone are shown under each violin plot

common metrics and the inferences which could be made from such studies relative to migration and survival of untagged smolts. The results suggest that there is a detectable negative effect on survival and migration rates when fish are only allowed short recovery times post-surgery before release. We found that in this first experiment, capturing juveniles in the fall, holding them in captivity over the winter and releasing back to the river in the spring immediately after a tagging intervention imparted a very strong compromise on survival immediately post-release. Although we might suspect the manipulation, transport, and short period of acclimation prior to release would be stressful to all fish, immediate short-term survival was not compromised in the winter hatchery treatment subjected to the same handling procedures, absent the tagging.

In comparison to the other treatment groups, it is unclear why the spring hatchery smolts experienced

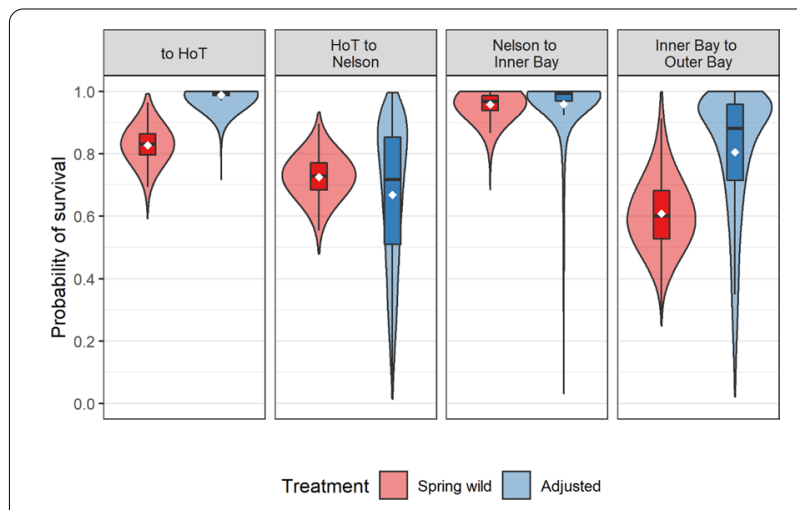

Fig. 5 Posterior distributions of estimated probability of survival between gates for the spring wild treatment and the adjusted survival of spring wild treatment after correcting for hatchery and post-recovery time effects. Violin plots are interpreted as in Fig. 4

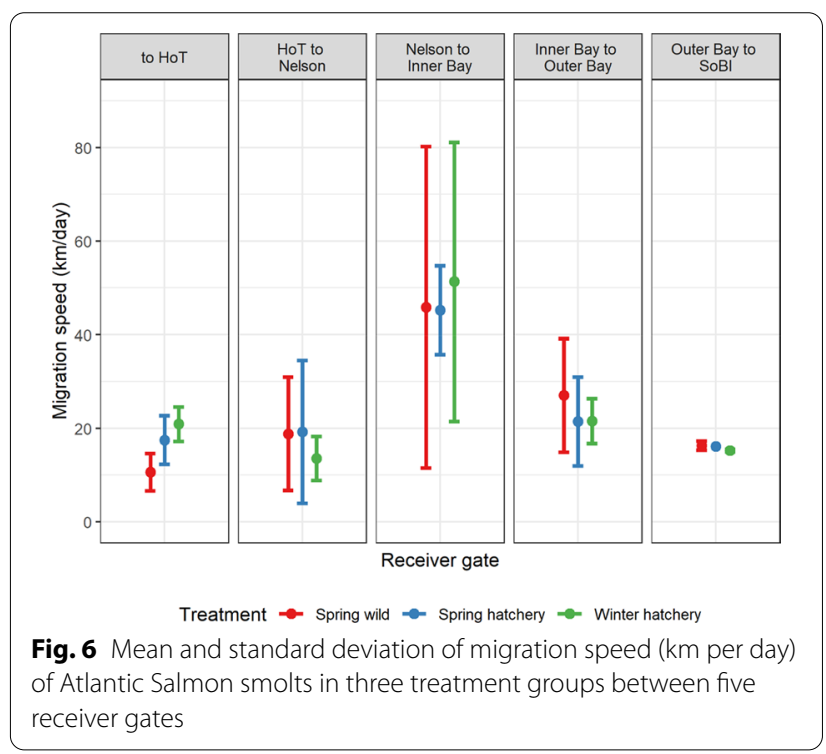

such low short-term survival post-release. Both hatchery treatments underwent the same transportation to and release protocols at the release site. As well, the wild

Table 3 Survival odds ratio of tagged Atlantic Salmon smolts from release to exit of Miramichi Bay and from the head of tide (HoT) area to exit of Miramichi Bay for three treatments

\begin{tabular}{|c|c|c|c|}
\hline \multirow[t]{2}{*}{ Experimental effect } & \multirow[t]{2}{*}{ Treatment comparison } & \multicolumn{2}{|l|}{ Odds ratio of survival } \\
\hline & & $\begin{array}{l}\text { Release to Outer Bay median; } \\
\text { (5th to } 95 \text { th percentile); } \\
\text { prob. }<=1 \text { ) }\end{array}$ & $\begin{array}{l}\text { HoT to Outer Bay median; (5th } \\
\text { to } 95 \text { th percentile); prob. }<=1 \text { ) }\end{array}$ \\
\hline & Winter hatchery tagged relative to spring wild tagged & $1.38 ;(0.86$ to 2.18$) ; p=0.13$ & 1.34 (0.85 to 2.06$) p=0.14$ \\
\hline Recovery time effect & $\begin{array}{l}\text { Winter hatchery tagged relative to spring hatchery } \\
\text { tagged }\end{array}$ & $2.53(1.39$ to 5.13$) p=0.01$ & $\begin{array}{l}1.47(0.89 \text { to } 2.79) \\
p=0.11\end{array}$ \\
\hline Hatchery effect & Spring wild tagged relative to spring hatchery tagged & $1.83(1.01$ to 3.71$) p=0.05$ & $1.10(0.66$ to 2.08$) p=0.39$ \\
\hline
\end{tabular}


spring smolts were also manipulated, transported for a shorter distance and time, and held in stream-side containers post-tagging. Surgery and handling protocols were identical between the spring wild and spring hatchery treatments, but these groups had very different estimated survivals to HoT from the release site. Therefore, it seems unlikely that solely transportation or surgery and handling protocols resulted in the high early mortality observed for the spring hatchery treatment. The most likely explanation for the high rate of early mortality of spring hatchery smolts is the result of cumulative stress from transportation and acclimation immediately followed by surgery. There is evidence that cumulative stress results in higher than expected mortality. For example, Handeland et al. [29] found that the interaction between osmotic stress and predator-induced stress resulted in higher rates of predation than the combined effects of predation and osmotic stress solely. Similarly, Dietrich et al. [30] present evidence, which suggests sublethal doses of organophosphates increase mortality rate of Chinook salmon in the presence of thermal stress. We suggest that the unexpectedly high mortality may have been due to the cumulative impacts of hatchery transport, surgery, and release to the wild following a short recovery period.

\section{Recovery time effects on migration speed and survival}

While there was no statistical difference in migration rates between the winter and spring hatchery treatments, there was a slightly faster mean migration speed for winter hatchery smolts between release and HoT. This was unexpected as the size of the spring hatchery treatment appeared to be much larger based on visual inspection pre-release and larger fish tend to have faster swimming speeds $[6,8]$. While small sample size prohibits any definitive conclusions, the slight difference could be indicative of a recovery time effect on the migration speed.

There was a noticeable recovery time effect on apparent survival from release to HoT. Although tag burden is most often viewed as the leading cause for reduced survival, the results from this study imply surgery may be the larger effect. Compared to the spring hatchery treatment, the winter hatchery group had higher tag burdens but with a much higher post-surgery recovery time they presented a higher survival rate. It is important to note, however, that we did not measure size of the winter hatchery group at time of release and their tag burdens were likely to have been exaggerated in relation to what would have been experienced at the time of release. Other studies have also drawn similar conclusions that surgery has a larger effect than tag burden. Studies have found no difference in mortality rates between tagged smolts and sham treatments (i.e. received surgery, yet no tag was implanted) also suggesting that surgery-related mortality may be more important than the size of the tag $[9,12]$.

Determining when and where mortality occurs is a key question, however, experimental manipulations such as those considered here, can affect the conclusions from the interpretation of acoustic telemetry data [31]. For example, a study presented by Chaput et al. [5] involved a 14-year multi-stock inference on the survival and migration of Atlantic Salmon smolts and post-smolts which suggested that differences between stocks migrating through a shared environment may be indicative of post-surgery acclimation factors. They also suggest that mortality associated with migration duration could be enhanced as a result of direct tagging effects and/or vulnerability to predation that occurred within the first 8 to 12 days of migration. While field-based studies and analysis of telemetry detections provide some information on survival and behaviour of tagged fish, they generally are inadequate to ascribe causal factors of mortality. Laboratory-based studies report similar time frames of surgery-related mortality as found in this study. Brunsdon et al. [12] found that the majority of the mortality of tagged Atlantic Salmon juveniles occurred within the first 10 days after surgery using the same tags used in this study (Vemco V8) and did not find any difference in survival rates between tagged smolts and a sham treatment. Ammann et al. [9] also found no difference in mortality rates between acoustically tagged individuals and a sham treatment. These results suggest that for smolts of the size used in these laboratory studies and in this experiment, mortality may be more likely a consequence of surgery-related effects as opposed to effects related to tag burden.

\section{Hatchery effects on migration speed and survival}

The juvenile salmon held in the hatchery were collected from the wild and held in captivity for a period of less than 6 months. Despite this relatively short-term holding period, we did observe significantly faster migration rates associated with captivity through the freshwater zone of migration. The larger size of the hatchery held smolts in comparison to spring wild smolts may partially explain the faster migration speed observed. Many studies have found a positive relationship between fork length and speed of Atlantic Salmon [22, 32, 33] and fish with higher tag burdens tend to have slower swimming speeds $[6,8]$. However, the difference in migration speed was only noted for survivors from release to HoT ( $<5$ days). This suggests that migration rate in freshwater to the estuary may be related to fork length, whereas migration rate through the estuary is conditioned by other factors 
such as variation in smoltification stage and acclimation to saltwater [34].

In general, wild smolt survival rates tend to be higher than hatchery-reared smolts, interpreted to be a consequence of poorer foraging and predator avoidance abilities of hatchery-reared smolts [35-38]. The effect of the hatchery holding (i.e. the spring wild relative to the spring hatchery treatment) appeared to negatively impact survival within the same zone of the river in which migration speed appeared to have been affected, between release and HoT. Jokikokko et al. [39] reported that survival of wild smolt and hatchery-reared Atlantic Salmon released as parr was twice that of hatchery-reared Atlantic Salmon released as smolts. Thorstad et al. [40] found that hatchery released smolts suffered approximately 50 percent mortality near the transition from fresh to salt water and imply that hatchery rearing of these fish may have resulted in poor predator avoidance as the vast majority of mortality in their study was likely due to piscine predators.

Most of the comparisons of wild versus hatchery survivals and behaviour are from studies in which the hatchery-reared smolts originated from spawning, hatching and rearing in the hatchery environment. We found no information regarding the impacts of short-term captive holding of wild fish on their subsequent behaviour and survival once released back into their natal river. There is, however, evidence from this study that some effects of captivity may manifest themselves even for relatively short periods of captivity.

\section{Adjusted survival}

The negative effect of the tagging procedure on survival after controlling for a hatchery effect is quite apparent in the very early stages of the migration, between release and $\mathrm{HoT}$ and to a lesser and more uncertain degree between the inner and outer bay zone. Our results suggest that smolt survival, after adjusting for the hatchery and recovery time effects, could have been greater than 95\% and nearly $90 \%$ through the freshwater and bay regions of the migration, respectively. The uncertainty in these estimates, primarily resulting from higher than expected spring hatchery mortality, limits our ability to suggest these effects are short-lived, however, we have presented information from both field and laboratory settings which suggests that direct and indirect tagging related mortality is temporally short-lived or a result of increased stress when transitioning through different environments.

The effect of the tag burden on the survival and behaviour of smolts was not quantified in this study. Tag burden has been extensively investigated and results have shown mortality increases with tag burden while swimming speed and predator avoidance decrease [6-8, 41]. Studies have also reported that larger tagged smolts have greater survival during the early stages of migration compared to smaller counterparts [5]. However, this study found the larger spring hatchery smolts had lower survival compared to the smaller spring wild and winter hatchery treatments but hatchery and recovery time effects likely influenced results. Furthermore, there was also no evidence that larger smolts within each treatment had higher survival rates (see Additional file 2; Figure S1). Nevertheless, the much higher mortality of the spring hatchery treatment was surprising as larger smolts were expected to have greater survival due to a reduced vulnerability to predators and a reduced tag burden $[5,36$, 42].

Previous studies have found that acoustically tagged wild Atlantic Salmon smolt survival through freshwater is improved by releasing fish in the evening in comparison to the morning [18]. We examined and did not find any evidence of differences in inferred survival rates of smolts released during the day or the late evening. This lack of effect may be due to the majority of the current study site being within the estuary and ocean which corresponds to areas where daytime migration patterns tend to dominate $[19,20,43]$. Day versus night-release effects may be important in areas where visual predators are in closer proximity to the release site or where there is a substantial freshwater migration phase which tends to be nocturnal for salmon smolts.

\section{Conclusion}

The objective of most acoustic telemetry studies is to quantify survival and behaviour of tagged individuals to infer the survival and behaviour of untagged and un-manipulated animals [22]. In this experiment, we examined the effects post-surgery recovery time on the migratory behaviour and inferred survival of tagged animals post-release. We found that allowing for a long post-surgery recovery period can improve the survival rates of tagged smolts relative to smolts with only a short recovery time post-surgery. There is evidence of an immediate short-term improvement in survival as well as a later benefit as smolts moved from brackish water into a more saline environment, a stressful environmental transitional zone. In order to have a treatment group with a long recovery period, we captured juveniles from the wild and held them in captivity for a relatively short overwinter period. This may have introduced unintended and undesired effects on behaviour and survival of individuals post-release. However, the results from this 1-year study suggest that the effects of captivity if present are minor compared to the effects related to surgery and short recovery times. An alternate experimental design 
that would provide a long recovery period without captivity would involve capturing, tagging and releasing in the late fall salmon juveniles of an appropriate size to accommodate the acoustic tags and that would be indicative of a high likelihood of becoming a smolt the following spring. The long recovery treatment group would then consist of those fall-tagged juveniles which survived and became smolts and were detected at a key receiver array in freshwater. This treatment group could be monitored in concert with the reference treatment involving capture, tagging and releasing actively migrating smolts but with a short recovery period. Furthermore, different sized tags could also be incorporated into the proposed study designs to examine the effects of tag burden in addition to the tagging (i.e. surgical) effects.

Acoustic telemetry studies of wild fish will always introduce a certain degree of bias as they involve the manipulation of animals. Provided the bias is consistent over time, which requires establishing and respecting standardized experimental procedures and protocols, long-term multi-stock telemetry studies such as that presented by Chaput et al. [5], may provide relevant and applicable relative trends in population and life history rates which can be inferred to be representative of characteristics of un-manipulated populations. However, quantifying the bias introduced through manipulation is most important in short term and/or single stock studies and experiments, such as the one reported here.

\section{Supplementary Information}

The online version contains supplementary material available at https://doi. org/10.1186/s40317-020-00228-6.

Additional file1. Effect of size of smolts at taggingon subsequent detections.

Additional file 2 Figure S1. Cumulative distribution of Atlantic Salmon smolt fork lengths $(\mathrm{cm})$ at time of release and detected at sequential receiver gates for the three treatment groups. Day release and night release represent the wild spring tagging group

\section{Acknowledgements}

We would like to thank Miramichi Salmon Association for their contribution to the collection of pre-smolt juveniles and smolts as well as the captive rearing at the hatchery. We would also like to thank Atlantic Salmon Federation staff for assistance in the tagging of smolts and deployment of acoustic receivers.

\section{Authors' contributions}

$J D, J C$, and GC conceived the project and created the project design. EBB, JD and $\mathrm{HD}$ wrote the manuscript. JD, EBB, and GC performed statistical analyses. All authors revised the manuscript and provided comments on design for publication. All authors read and approved the final manuscript.

\section{Funding}

Funding for the purchase of acoustic tags was provided by the Atlantic Salmon Federation and Fisheries and Oceans Canada.
Availability of data and materials

Data will be made available upon request.

\section{Ethics approval and consent to participate}

All methodologies used during this study were approved by an animal care committee and followed the Canadian Council of Animal Care guidelines.

\section{Consent for publication}

Not applicable.

\section{Competing interests}

The authors state that there are no competing interests.

\section{Author details}

1 Atlantic Salmon Federation, 15 Rankine Mill Road, Chamcook, NB E5B 3A9, Canada. ${ }^{2}$ Fisheries and Oceans Canada, 1 Challenger Dr, Dartmouth, NS B2Y 4A2, Canada. ${ }^{3}$ Fisheries and Oceans Canada, 343 University Ave, Moncton, NB E1C 9B6, Canada. ${ }^{4}$ Wilfrid Laurier University, 75 University Avenue West, Waterloo, Ontario N2L 3C5, Canada. ${ }^{5}$ Miramichi Salmon Association, 485 Route 420, South Esk, NB E1V 4L9, Canada.

Received: 23 September 2020 Accepted: 21 December 2020

Published online: 29 January 2021

\section{References}

1. Finstad B, Økland F, Thorstad EB, Bjørn PA, McKinley RS. Migration of hatchery-reared Atlantic Salmon and wild anadromous Brown Trout postsmolts in a Norwegian fjord system. J Fish Biol. 2005;66:86-96.

2. Kocik JF, Hawkes JP, Sheehan TF, Music PA, Beland KF. Assessing estuarine and coastal migration and survival of wild Atlantic Salmon smolts from the Narraguagus River, Maine Using Ultrasonic Telemetry. Am Fish Soc Symp. 2009;69:293-310

3. Lefévre M, Stokesbury MJW, Whoriskey FG, Dadswell MJ. Migration of Atlantic Salmon smolts and post-smolts in the Rivière Saint-Jean, QC north shore from riverine to marine ecosystems. Environ Biol Fishes. 2013;96:1017-28.

4. Michel CJ, Ammann AJ, Lindley ST, Sandstrom PT, Chapman ED, Thomas MJ, Singer GP, Klimley AP, MacFarlane RB. Chinook Salmon outmigration survival in wet and dry years in California's Sacramento River. Can J Fish Aquat Sci. 2015;72:1749-59.

5. Chaput G, Carr J, Daniels J, Tinker S, Jonsen I, Whoriskey F. Atlantic Salmon (Salmo salar) smolt and early post-smolt migration and survival inferred from multi-year and multi-stock acoustic telemetry studies in the Gulf of St. Lawrence, northwest Atlantic. ICES J Marine Sci. 2018:76(4):1107-21.

6. Adams NS, Rondorf DW, Evans SD, Kelly JE, Perry RW. Effects of surgically and gastrically implanted radio transmitters on swimming performance and predator avoidance of juvenile Chinook Salmon (Onchorhynchus tshawytscha). Can J Fish Aquat Sci. 1998;55:781-7.

7. Lacroix GL, Knox D, McCurdy P. Effects of implanted dummy acoustic transmitters on juvenile Atlantic Salmon. Trans Am Fish Soc. 2004;133:211-20. https://doi.org/10.1577/T03-071.

8. Brown RS, Geist DR, Deters KA, Grassell A. Effects of surgically implanted acoustic transmitters $>2 \%$ of body mass on the swimming performance, survival and growth of juvenile Sockeye and Chinook Salmon. J Fish Biol. 2006:69:1626-38. https://doi.org/10.1111/j.1095-8649.2006.01227x.

9. Ammann AJ, Michel CJ, MacFarlane RB. The effects of surgically implanted acoustic transmitters on laboratory growth, survival and tag retention in hatchery yearling Chinook Salmon. Environ Biol Fishes. 2013;96:135-43. https://doi.org/10.1007/s10641-011-9941-9.

10. Daniels J, Chaput G, Carr J. Estimating consumption rate of Atlantic Salmon smolts (Salmo salar) by Striped Bass (Marone saxatilis) in the Miramichi River estuary using acoustic telemetry. Can J Fish Aquat Sci. 2018;75(11):1811-22.

11. Daniels J, Sutton S, Webber D, Carr J. Extent of predation bias present in migration survival and timing of Atlantic salmon smolt (Salmo salar) as suggested by a novel acoustic tag. Animal Biotelemetry. 2019;7(1):16.

12. Jepsen N, Koed A, Thorstad EB, Baras E. Surgical implantation of telemetry transmitters in fish: how much have we learned? Hydrobiologia. 2002:483:239-48. 
13. Brunsdon EB, Daniels J, Hanke A, Carr J. Tag retention and survival of Atlantic salmon (Salmo salar) smolts surgically implanted with dummy acoustic transmitters during the transition from fresh to salt water. ICES J Mar Sci. 2019;76(7):2471-80

14. Sandstrom PT, Ammann AJ, Michel C, Singer G, Chapman ED, Lindley S, MacFarlane RB, Klimley AP. Growth, survival, and tag retention of steelhead trout (Oncorhynchus mykiss) and its application to survival estimates. Environ Biol Fishes. 2013;96:145-64. https://doi.org/10.1007/ s10641-012-0051-0.

15. Moore A, Ives S, Mead TA, Talks L. The migratory behaviour of wild Atlantic Salmon (Salmo salar L.) smolts in the River Test and Southampton Water, southern England. Hydrobiologia. 1998;371(372):295-304.

16. Oldenburg EW, Colotelo AH, Brown RS, Eppard MB. Holding of juvenile salmonids for surgical implantation of electronic tags: a review and recommendations. Rev Fish Biol Fisheries. 2011;21:35-42. https://doi. org/10.1007/s11160-010-9186-2.

17. Panther JL, Brown RS, Gaulke GL, Woodley CM, Deters KA. Influence of incision location on transmitter loss, healing, incision lengths, suture retention, and growth of juvenile Chinook Salmon. US Army Corps of Engineers, Portland District, Portland, OR, USA. 2010;PNNL-19192:1-44.

18. Vollset KW, Barlaup BT, Normann ES. Release during night enhances survival of wild Atlantic salmon smolts. Fish Manage Ecol. 2017;24:256-64.

19. McCormick SD, Hansen LP, Quinn TP, Saunders RL. Movement, migration, and smolting of Atlantic Salmon (Salmo salar). Can J Fish Aquat Sci. 1998;55(Suppl. 1):77-92.

20. Ibbotson AT, Beaumont WRC, Pinder A, Welton S, Ladle M. Diel migration patterns of Atlantic Salmon smolts with particular reference to the absence of crepuscular migration. Ecol Freshw Fish. 2006;15:544-51.

21. Roberts LJ, Taylor J, Gough PJ, Forman DW, Garcia de Leaniz C. Night stocking facilitates nocturnal migration of hatchery-reared Atlantic Salmon, Salmo salar, smolts. Fisheries Management and Ecology. 2009;16:10-13.

22. Thorstad EB, Whoriskey F, Uglem I, Moore A, Rikardsen AH, Finstad B. A critical life stage of the Atlantic Salmon Salmo salar: behaviour and survival during the smolt and initial post-smolt migration. J Fish Biol. 2012;81:500-42.

23. Hansen LP, Jonsson B. Downstream migration of hatchery reared smolts of Atlantic Salmon Salmo salar L. in the River Imsa. Aquaculture. 1985;45:237-48.

24. Chaput G, Douglas SG, Hayward J. Biological Characteristics and Population Dynamics of Atlantic Salmon (Salmo salar) from the Miramichi River, New Brunswick, Canada. DFO Canadian Science Advisory Secretariat Research Document. 2016;2016/029. https://waves-vagues.dfo-mpo. gc.ca/Library/363989.pdf

25. Holm S. A simple sequentially rejective multiple test procedure. Scand J Stat. 1979;6(2):65-70

26. Royle JA. Modelling individual effects in the Cormack-Jolly-Seber model: a state-space formulation. Biometrics. 2008;64:364-70.

27. Kéry M, Schaub M. Bayesian population analysis using WinBUGS: A hierarchical perspective. Oxford: Academic press; 2012.

28. Lunn, D., Jackson, C., Best, N., Thomas, A., and Spiegelhalter, D. 2013. The BUGS Book A Practical Introduction to Bayesian Analysis. Chapman and Hall. 381 p.

29. Handeland SO, Järvi T, Fernö A, Stefansson SO. Osmotic stress, antipredatory behaviour, and mortality of Atlantic salmon (Salmo salar) smolts. Can J Fish Aquat Sci. 1996;53(12):2673-80.
30. Dietrich JP, Van Gaest AL, Strickland SA, Arkoosh MR. The impact of temperature stress and pesticide exposure on mortality and disease susceptibility of endangered Pacific salmon. Chemosphere. 2014;108:353-9. https://doi.org/10.1016/j.chemosphere.2014.01.079.

31. Klinard NV, Matley JK, Halfyard EA, Connerton M, Johnson TB, Fisk AT. Poststocking movement and survival of hatchery-reared bloater (Coregonus hoyi) reintroduced to Lake Ontario. Freshw Biol. 2020;65:1073-85. https:// doi.org/10.1111/fwb.13491.

32. Tang J, Wardle CS. Power output of two sizes of Atlantic Salmon (Salmo salar) at their maximum sustained swimming speeds. J Exp Biol. 1992;166:33-46.

33. Mork KA, Gilbey J, Hansen LP, Jensen AJ, Jacobsen JA, Holm M, Holst JC, O’Maoiléidigh N, Vikebø F, McGinnity P, Melle W, Thomas K, Verspoor E, Wennevik V. Modelling the migration of post-smolt Atlantic Salmon (Salmo salar) in the Northeast Atlantic. ICES J Marine Science. 2012;69:1616-1624

34. Lacroix GL, McCurdy P. Migratory behaviour of post-smolt Atlantic salmon during initial stages of seaward migration. J Fish Biol. 1996:49(6):1086-101.

35. Jonsson $B$, Jonsson N, Hansen LP. Differences in life history and migratory behaviour between wild and hatchery-reared Atlantic Salmon in nature. Aquaculture. 1991;98:69-78.

36. Jonsson N, Jonsson B, Hansen LP. The marine survival and growth of wild and hatchery-reared Atlantic Salmon. J Appl Ecol. 2003;40:900-11.

37. Saloniemi I, Jokikokko E, Kallio-Nyberg I, Jutila E, Pasanen P. Survival of reared and wild Atlantic Salmon smolts: size matters more in bad years. ICES J Mar Sci. 2004;61:782-7.

38. Larsson S, Linnansaari T, Vatanen S, Serrano L, Haikonen A. Feeding of wild and hatchery reared Atlantic Salmon (Salmo salar L.) smolts during downstream migration. Environmental Biology of Fishes. 2011;92(3):361-369.

39. Jokikokko E, Kallio-Nyberg I, Saloniemi I, Jutila E. The survival of semi-wild, wild and hatchery-reared Atlantic salmon smolts of the Simojoki River in the Baltic Sea. J Fish Biol. 2006;68(2):430-42.

40. Thorstad EB, Whoriskey F, Rikardsen AH, Aarestrup K. Aquatic nomads: the life and migrations of the Atlantic salmon. Atlantic salmon ecology. 2011;1(6).

41. Brown RS, Harnish RA, Carter KM, Boyd JW, Deters KA, Eppard MB. An evaluation of the maximum tag burden for implantation of acoustic transmitters in juvenile Chinook Salmon. North Am J Fish Manag. 2010;30:499-505. https://doi.org/10.1577/M09-038.1.

42. Stokesbury MJ, Lacroix GL. High incidence of hatchery origin Atlantic Salmon in the smolt output of a Canadian River. ICES J Mar Sci. 1997;54:1074-81.

43. Hvidsten NA, Jensen AJ, Vivas H, Bakke $\varnothing$, Heggberget TG. Downstream migration of Atlantic Salmon smolts in relation to water flow, water temperature, moon phase and social interaction. Nordic Journal of Freshwater Research. 1995;70:38-48.

\section{Publisher's Note}

Springer Nature remains neutral with regard to jurisdictional claims in published maps and institutional affiliations.

Ready to submit your research? Choose BMC and benefit from

- fast, convenient online submission

- thorough peer review by experienced researchers in your field

- rapid publication on acceptance

- support for research data, including large and complex data types

- gold Open Access which fosters wider collaboration and increased citations

- maximum visibility for your research: over $100 \mathrm{M}$ website views per year

At BMC, research is always in progress.

Learn more biomedcentral.com/submissions 